\title{
Climate change and plankton phenology in freshwater: current trends and future commitments
}

\author{
Csaba VADADI-FÜLÖP, ${ }^{1 *}$ Levente HUFNAGEL ${ }^{2}$ \\ ${ }^{1}$ Hungarian Scientific Research Fund Office, Czuczor u. 10, 1093 Budapest; ${ }^{2}$ Adaptation to Climate Change Research Group, Corvinus \\ University of Budapest, Villányi út 29-43, 1118 Budapest, Hungary \\ *Corresponding author: vadfulcsab@gmail.com
}

\begin{abstract}
A solid body of empirical, experimental and theoretical evidence accumulated over recent years indicated that freshwater plankton experienced advance in phenology in response to climate change. Despite rapidly growing evidence for phenological changes, we still lack a comprehensive understanding of how climate change alters plankton phenology in freshwater. To overcome current limitations, we need to shed some light on trends and constraints in current research. The goal of this study is to identify current trends and gaps based on analysis of selected papers, by the help of which we can facilitate further advance in the field. We searched the literature for plankton phenology and confined our search to studies where climate change has been proposed to alter plankton phenology and rates of changes were quantified. We did not restrict our search for empirical contributions; experimental and theoretical studies were considered as well. In the following we discuss the spatio-temporal setting of selected studies, contributions of different taxonomic groups, emerging methodological constraints, measures of phenological trends; and finally give a list of recommendations on how to improve our understanding in the field. The majority of studies were confined to deep lakes with a skewed geographical distribution toward Central Europe, where scientists have long been engaged in limnology. Despite these findings, recent studies suggest that plankton in running waters may experience change in phenology with similar magnitude. Average rate of advancement in phenology of freshwater plankton exceeded those of the marine plankton and the global average. Increasing study duration was not coupled either with increasing contribution of discontinuous data or with increasing rates of phenological changes. Future studies may benefit from i) delivering longterm data across scientific and political boundaries; ii) extending study sites to broader geographical areas with a more explicit consideration of running waters; iii) applying plankton functional groups; iv) increasing the application of satellite data to quantify phytoplankton bloom phenology; v) extending analyses of time series beyond the spring period; vi) using various metrics to quantify variation in phenology; vii) combining empirical, experimental and theoretical approaches; and last but not least viii) paying more attention to emergence dynamics, nonresponding species and trophic mismatch.
\end{abstract}

Key words: clear-water phase, phenological metrics, seasonal timing, trophic mismatch, global warming.

Received: April 2013. Accepted: July 2013.

\section{INTRODUCTION}

There is emerging evidence that species of a broad range of taxonomic groups experienced advance in phenology over recent decades with a global average ranging from 2.3 to 5.1 days per decade as a response to global warming (Parmesan and Yohe, 2003; Root et al., 2003; Parmesan, 2007). Plankton phenology is no exception to the rule, and thus it can be a useful indicator of climate change (Hays et al., 2005; Richardson, 2008). When the time-lag between population peaks of prey and predator increases, a mismatch between food availability and food requirement can arise (Cushing, 1969). While there may be a positive publication bias toward changes in phenology attributed to climate change, it is increasingly recognised that climate change can disrupt existing synergies of trophic interactions by triggering phenological events in an asynchronous way (Durant et al., 2007; Thackeray et al., 2010). Evidence for those responses ranged from the trophic mismatch between caterpillars and great tits (Parus major) (Visser et al., 2006), through the decoupling of phenologies of plants and their herbivores (Liu et al., 2011), to the disruption of plant-pollinator interactions (Memmott et al., 2007). In freshwater, such a mismatch between the consumer and its resource may bring to the absence of the spring clear-water phase (CWP) (De Senerpont Domis et al., 2007) and thus may have severe consequences for the food web. The CWP, one of the most spectacular events in plankton succession, can be fairly predictable and is caused by zooplankton grazing (Sommer et al., 1986). The onset of the CWP, measured as a Secchi disk reading, represents an emerging measure and a sophisticated way of thinking about plankton phenology (Scheffer et al., 2001; Straile, 2002). Straile (2002) has convincingly demonstrated how the North Atlantic oscillation (NAO) appeared to synchronise the timing of the CWP over large areas.

Despite rapidly growing evidence for phenological 
changes, we still lack a comprehensive understanding of how climate change alters plankton phenology in freshwater. Recent reviews are confined to the impact of climate change on zooplankton in general and only briefly discuss phenology (Wojtal-Frankiewicz, 2012; Vadadi-Fülöp et al., 2012). A general finding, what one would expect also, is that species experience an advance in phenology in response to climate warming, but the rate of advancement and the underlying mechanisms vary over species and study sites. To overcome current limitations, we need to shed some light on trends and constraints in current research. The goal of this study is neither a comprehensive review of the existing literature, nor a meta-analysis of previously published data, rather an analysis of spatio-temporal settings and methodologies of selected studies so as to identify current trends and gaps, by the help of which we can facilitate further advance in the field.

We searched the literature for plankton phenology and confined our search to studies where climate change has been proposed to alter plankton phenology and rates of changes were quantified. We did not restrict our search for empirical contributions; experimental and theoretical studies were considered as well. We searched ISI Web of Knowledge using different filters, including among others phenology (topic) AND plankton (topic), mismatch (topic) AND plankton (topic), plankton (topic) AND seasonal (topic) AND climate change (topic), plankton (topic) AND succession (topic) AND climate change (topic). We also searched the references of the relevant papers thoroughly. In the end, we identified 55 papers, only 42 of those though met the criteria discussed above, i.e. quantify shifts in phenology. We restricted our literature search to papers published until April 2012. Beyond doubt, this list is not complete, we hope, however, that this is a representative subset of papers published on this topic.

First, we begin to consider the spatio-temporal setting of the studies, then we turn to methodological aspects (sampling frequency, used metrics to identify phenological changes in plankton, modelling approaches) so as to distinguish recent trends in the field. We close with a list of recommendations on how to improve our understanding in this cutting-edge research area.

\section{SPATIAL SETTING AND CONTRIBUTIONS OF DIFFERENT TAXONOMIC GROUPS}

The literature published on this topic was skewed toward lake plankton with the majority of studies $(66 \%)$ published on deep lakes (Tab. 1). Only two of the selected studies dealt with running waters (Danube River) both of which were purely modelling approaches. Most surveys covered Lakes Constance and Washington, both having a long history of limnological research. The geographical distribution of the studies published was biased as well with much of the findings derived from Germany, UK and the US. Only one study comes from Asia (Zhang et al., 2012) and another from Africa (Bergamino et al., 2007). Out of the studies with defined territories, $56 \%$ comes from Central Europe, 22\% from the UK and only 22\% from elsewhere. We found that the bulk of papers published on shallow lakes comes from Germany and the UK, resulting in the very same feature as demonstrated above for deep lakes. Shallow lakes included in this paper have relatively minor surface areas (Tab. 1), but see Lake Taihu (China) with a surface area of $2338 \mathrm{~km}^{2}$ as an exception. Deep lakes have much prestigious areas with a maximum of 32,600 $\mathrm{km}^{2}$ (Lake Tanganyika).

Diatoms and blue-greens were the most frequent taxa of phenological studies in phytoplankton. Algal studies used multi-species approaches more frequently than zooplankton studies. Much of our recent understanding about how climate change acts upon the phenology of zooplankton comes from Daphnia studies. Out of 42 studies, 14 dealt with Daphnia phenologies. It is important to note, however, that this number may increase significantly when we consider studies applying multi-species approaches. Three papers considered rotifers, 6 papers considered copepods and 6 cladocerans (beyond daphnids), respectively. Only one paper included phenology of ciliates. A considerable number of studies (11 papers) made an effort to tackle phytoplankton and zooplankton phenologies simultaneously. Those studies are really needed in a multi-piece puzzle such as the understanding of phenology under a warming climate.

\section{TIME SPAN, SAMPLING FREQUENCY AND PHENOLOGICAL METRICS}

Time span of studies ranged between 5 and 76 years with an average of 27 years (median $=23$ years) (data derived from monitoring studies only). We considered a data set continuous when data were available for each year; when there was a gap in the data, it was considered discontinuous. Fig. 1 shows the total number of studies (in \%) vs study duration. Interestingly, increasing levels of study duration did not increase the contribution of discontinuous data seriously. The highest proportion of discontinuous data emerged in studies lasting from 10 to 20 years. The time window of those time series encompasses the 1970s, 1980s and 1990s corresponding with the positive phase of the NAO index (Hurrell, 1995). In the UK, some studies date back to the early 1930s and 1940s. Again, the most long standing time series comes from Central Europe where scientists have long been engaged in limnology. A number of monitoring programmes started in the 1970s and 1980s followed by a decline in the 1990s (Fig. 2). The number of published time series will definitely further increase in the future when we consider the time-lag of publication.

Sampling frequencies varied from daily (remote sensing) to monthly intervals (Tab. 1). The majority of studies 


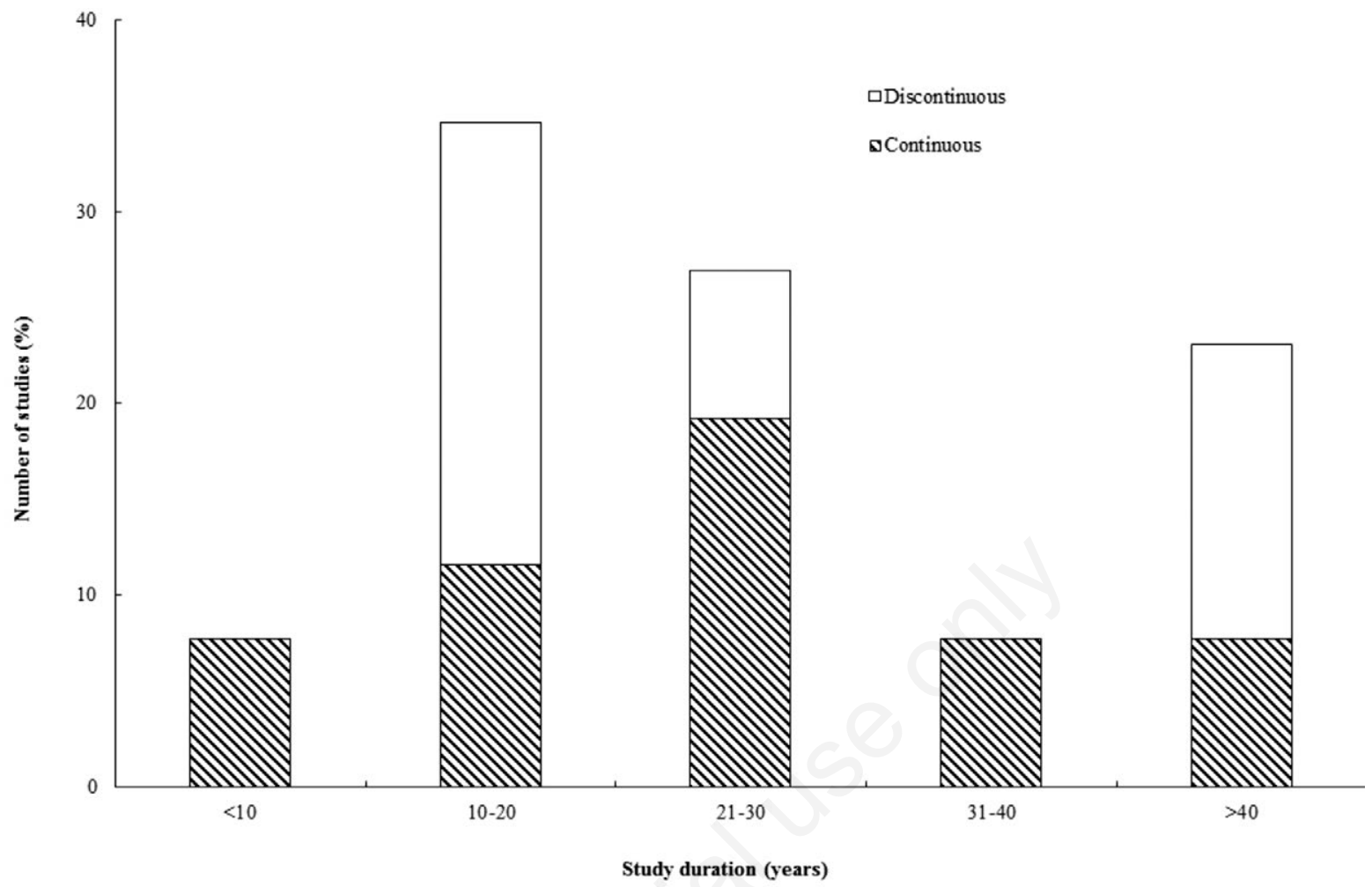

Fig. 1. Total number of continuous (data available from all years) and discontinuous (missing data) studies vs study duration.

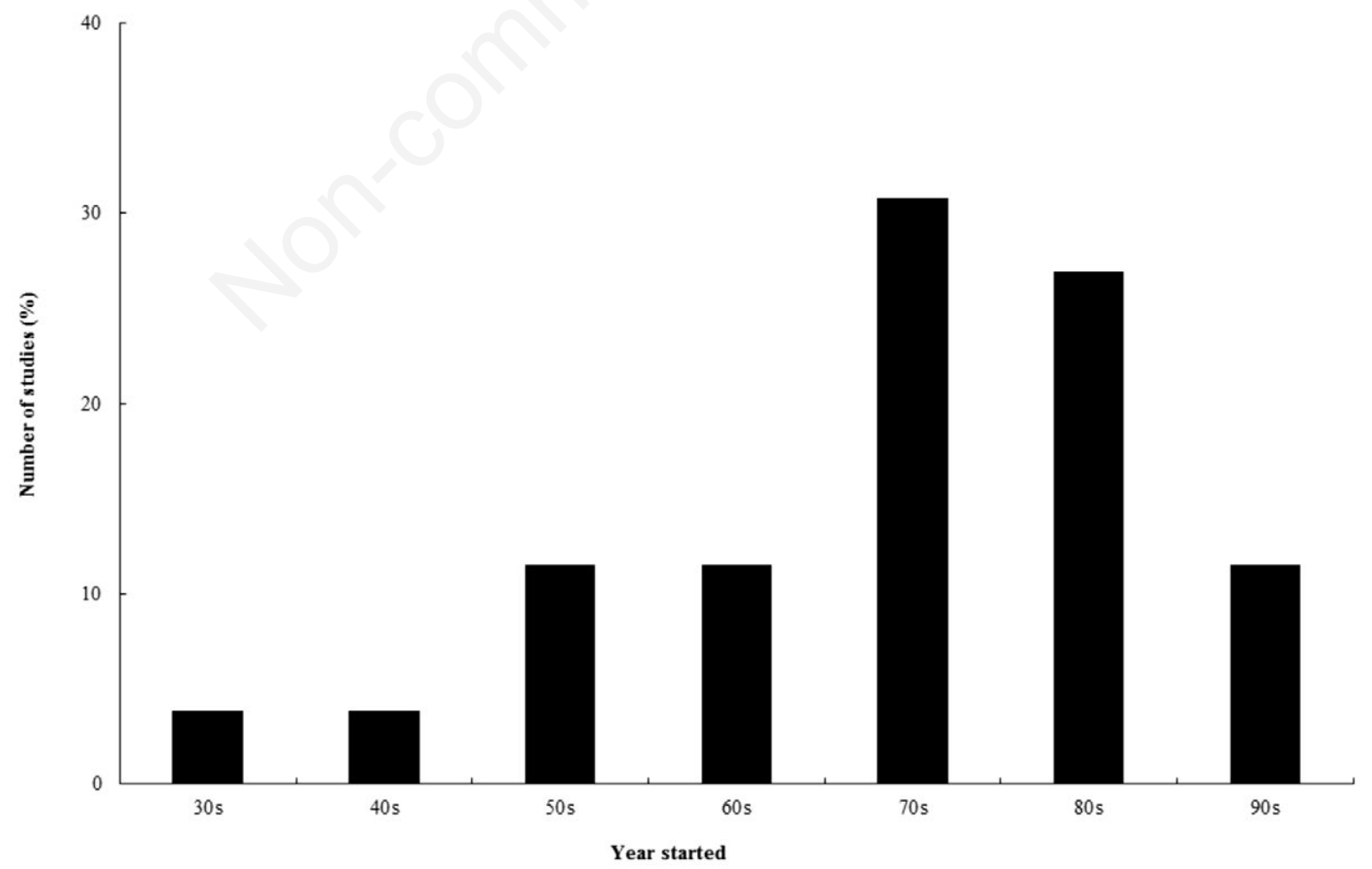

Fig. 2. Number of published studies $v s$ starting year of sampling programme. 
$(85 \%)$ derived their findings from samples collected at weekly-fortnightly intervals, at least during the growing season. Only three studies derived their findings from data collected at monthly intervals during the growing season. Of the selected studies, $31 \%$ considered the spring period only, either in a strict (March, April, May) or a wider sense (first half of the year). Sixty percent of papers took the whole year into consideration.

Out of the 42 selected papers, only 15 used more than one metrics for measuring shift in phenology. The most common metrics used was the day of maximum abundance of the population accounting for $67 \%$ of the selected papers. Other metrics were the undermentioned: central tendency method, Weibull-type function, onset of the bloom, end of the bloom, onset of the CWP, time of first and last observation, duration in the water column, and seasonal trend decomposition based on Loess (STL) smoothing procedure (Tab. 1). Following Thackeray et al. (2012), we defined whether relative or absolute thresholds were used to calculate the metrics (when possible) (Tab. 1). Thackeray et al. (2012) applied 10 methods, 9 of which resulted in a similar finding (earlier seasonal timing of Daphnia galeata populations) although with different rates of change (3.7-6.7 days per decade). It is important to note, however, that this study was based on a unique data set of Daphnia in Lake Windermere covering 76 years.

\section{EMPIRICAL, EXPERIMENTAL AND THEORETICAL CONTRIBUTIONS}

The majority of the selected studies derived their findings from long-term monitoring (55\%). Only three papers used either indoor or outdoor experiments. Twelve papers applied purely modelling approaches. In addition, three studies combined ecological modelling with an empirical approach, and one more combined modelling with experimental setup, respectively (Tab. 1).

Out of the 16 modelling approaches, three used the phytoplankton responses to environmental change (PROTECH) model including a number of variables, i.e. temperatures, nutrients, light, grazing effects, biomass loss because of settling and dilution. Only one paper (Mooij et al., 2007) used an ecosystem model (PCLake), which simulates the main nutrient and food web dynamics of a shallow lake including the most important biotic and abiotic interactions. Predator-prey models were applied to simulate the onset of the CWP with climatic forcing (Scheffer et al., 2001) and to understand how overwintering vs diapausing strategies in Daphnia determine match-mismatch in zooplankton-algae interactions (De Senerpont Domis et al., 2007). Sipkay et al. (2012) validated a strategic model of a theoretical algal community to field data and then developed a tactical model for phytoplankton communities in the Danube River by considering temperatures and light only. Such simple tactical models (Sipkay et al., 2008; Vadadi-
Fülöp et al., 2009) do not aimed to shed new light on a theory, rather favour considerable applicability. Still, those models are fairly useful because the vast number of variables complex models suppose they are often not available. Further approaches include hydrodynamically driven plankton models (Gaedke et al., 1998; Peeters et al., 2007a, 2007b), population models (Müller-Navarra et al., 1997; Huber et al., 2008; Schalau et al., 2008) and a biogeochemical model combined with an eutrophication model (Shimoda et al., 2011).

\section{QUANTITATIVE DATA OF PHENOLOGY SHIFT AND POSSIBLE DRIVERS BEHIND}

This paper is not aimed to serve as a meta-analysis of plankton phenology, i.e. we did not analyse raw data of phenological changes. With those constraints in mind, we give only a rough estimate of phenological changes documented and projected in plankton communities on the basis of the selected papers. Eight studies displayed subtle outcomes, either a forward or a backward shift in phenology depending on conditions. Some papers presented their findings as a function of temperature increase, i.e. peak advance per $1{ }^{\circ} \mathrm{C}$ warming (Müller-Navarra et al., 1997; Scheffer et al., 2001; Wagner and Benndorf, 2007; Elliott, 2012). The majority of studies ( $\mathrm{N}=32)$ demonstrated a forward shift in phenology (Tab. 1) ranging from 9 days in Leptodiaptomus ashlandi in Lake Washington (Winder and Schindler, 2004b) to 150 days in Bythotrephes longimanus in Lake Maggiore (Manca, 2011). Taking into consideration those 32 rates of phenological change, it resulted in a mean advancement of 38 days over the study period (when rates of changes were given both for the species and the community level in the same paper, only the latter was considered in the analysis). Only 6 taxa showed later seasonal timing (Tab. 1). In order to determine whether study duration affects final conclusions, we plotted rates of phenological changes (advancement only) against study duration (where possible). We found no linear trend within those variables, i.e. longer time series were not coupled with increasing rates of changes (Fig. 3; $\mathrm{N}=23$ ).

Furthermore, we calculated rates of phenological change per year, which resulted in a mean rate of 1.5 days per year (median $=0.7$ days per year; $\mathrm{N}=27$ ) considering rates of advancements and delays as well. Those calculations were not possible when study duration was not applicable (experiments, models) and when original data were given in change per ${ }^{\circ} \mathrm{C}$ warming instead of change over a time period (Tab. 1). Shallow and deep lake plankton experienced comparable rates of changes, however, seasonal timing in zooplankton (mean $=35$ days; $N=16$ ) slightly exceeded that of phytoplankton (mean $=21$ days; $\mathrm{N}=19$ ), although this difference nearly disappeared when rates were considered as day per year (1.5 days per year; $\mathrm{N}=12$, and 1.4 days per year; $\mathrm{N}=13$, respectively). 


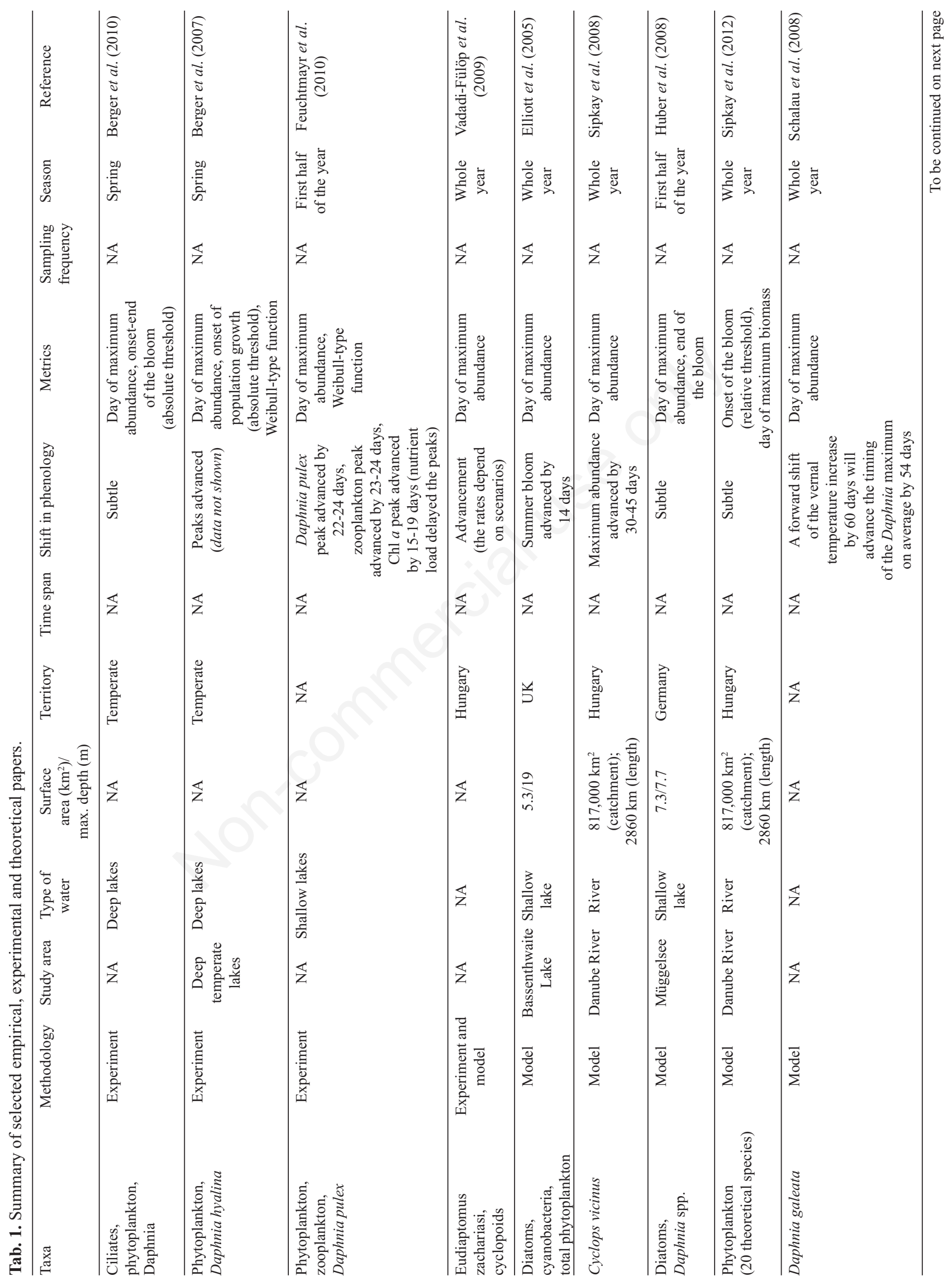




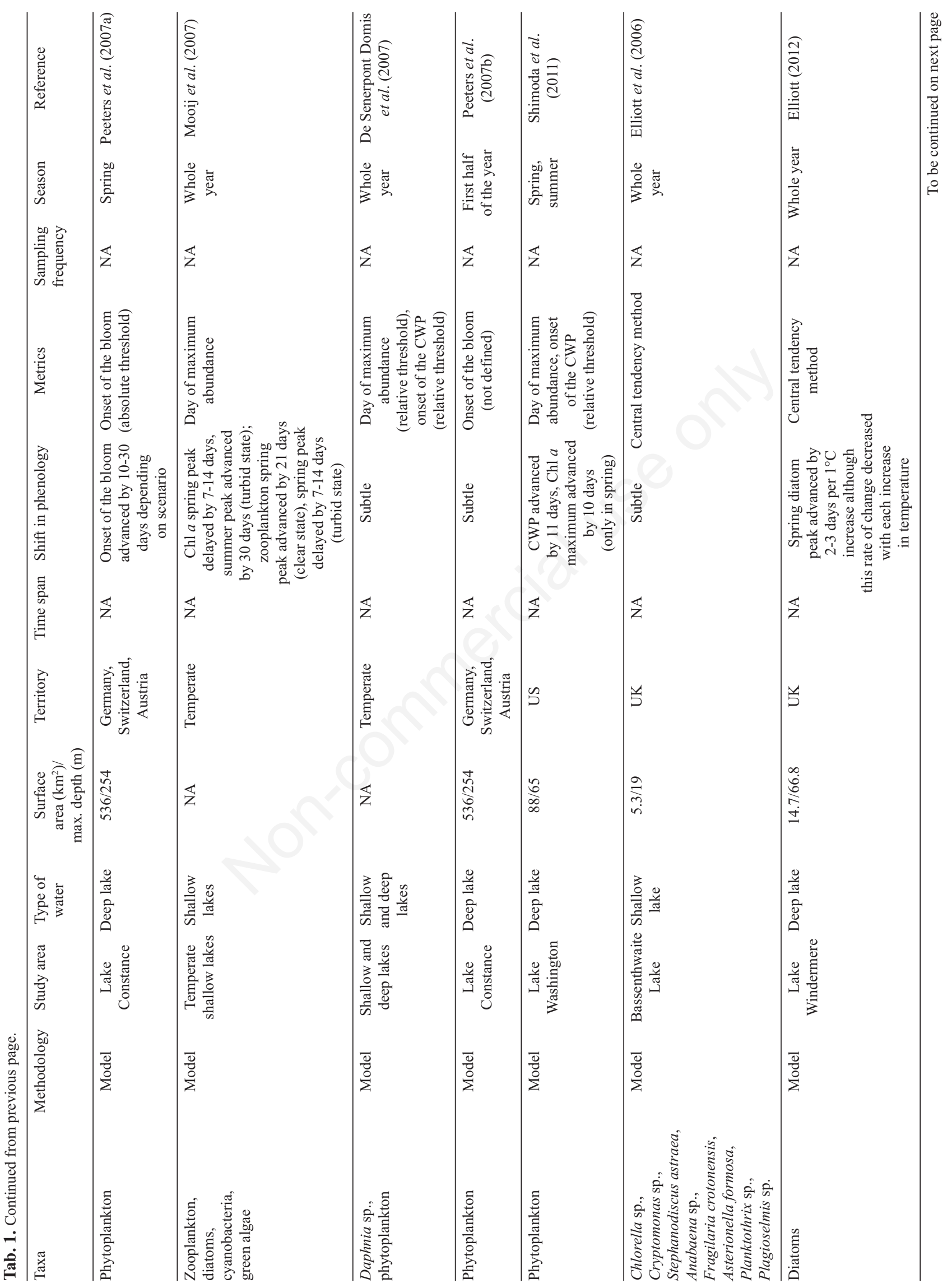




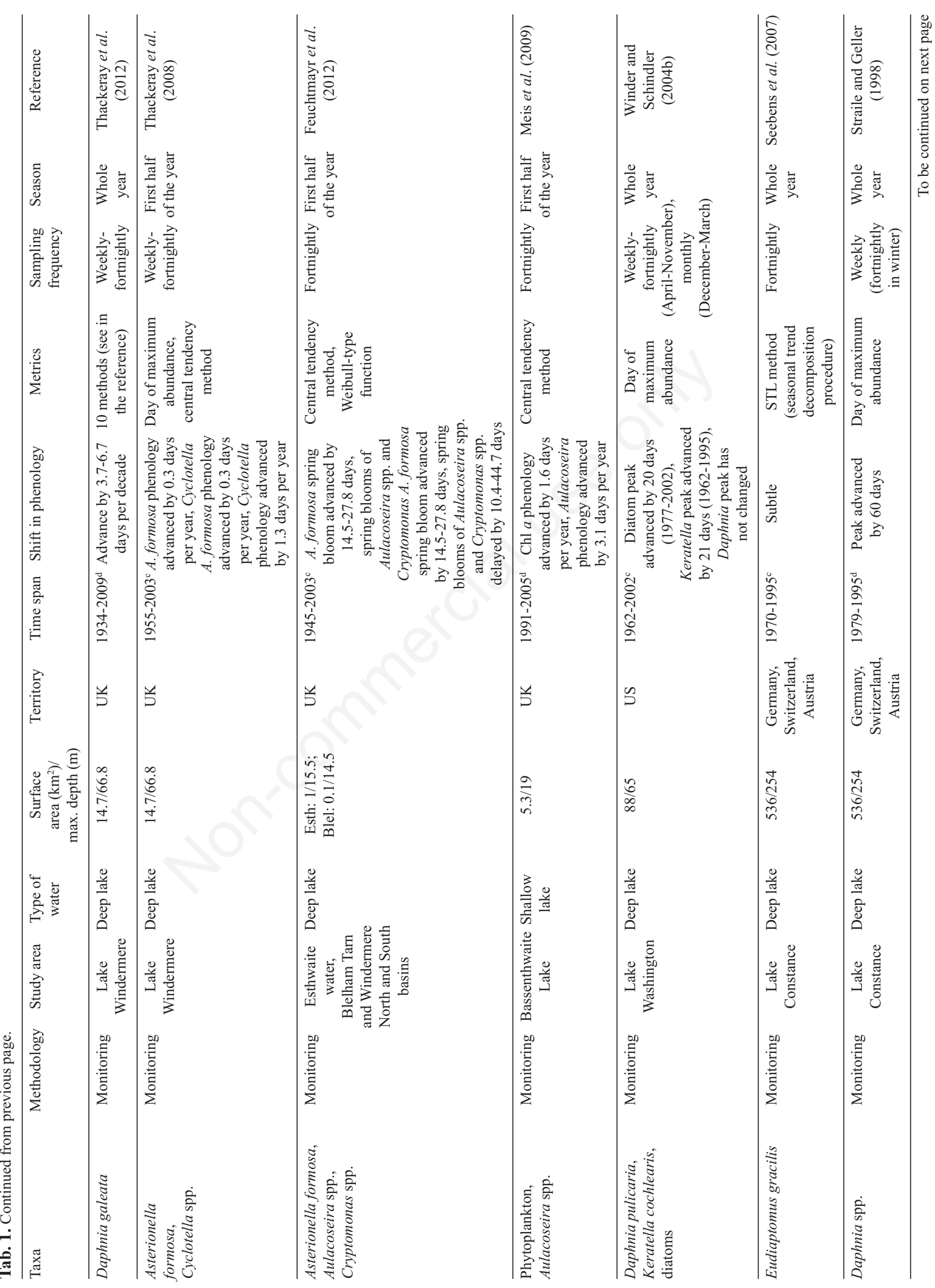




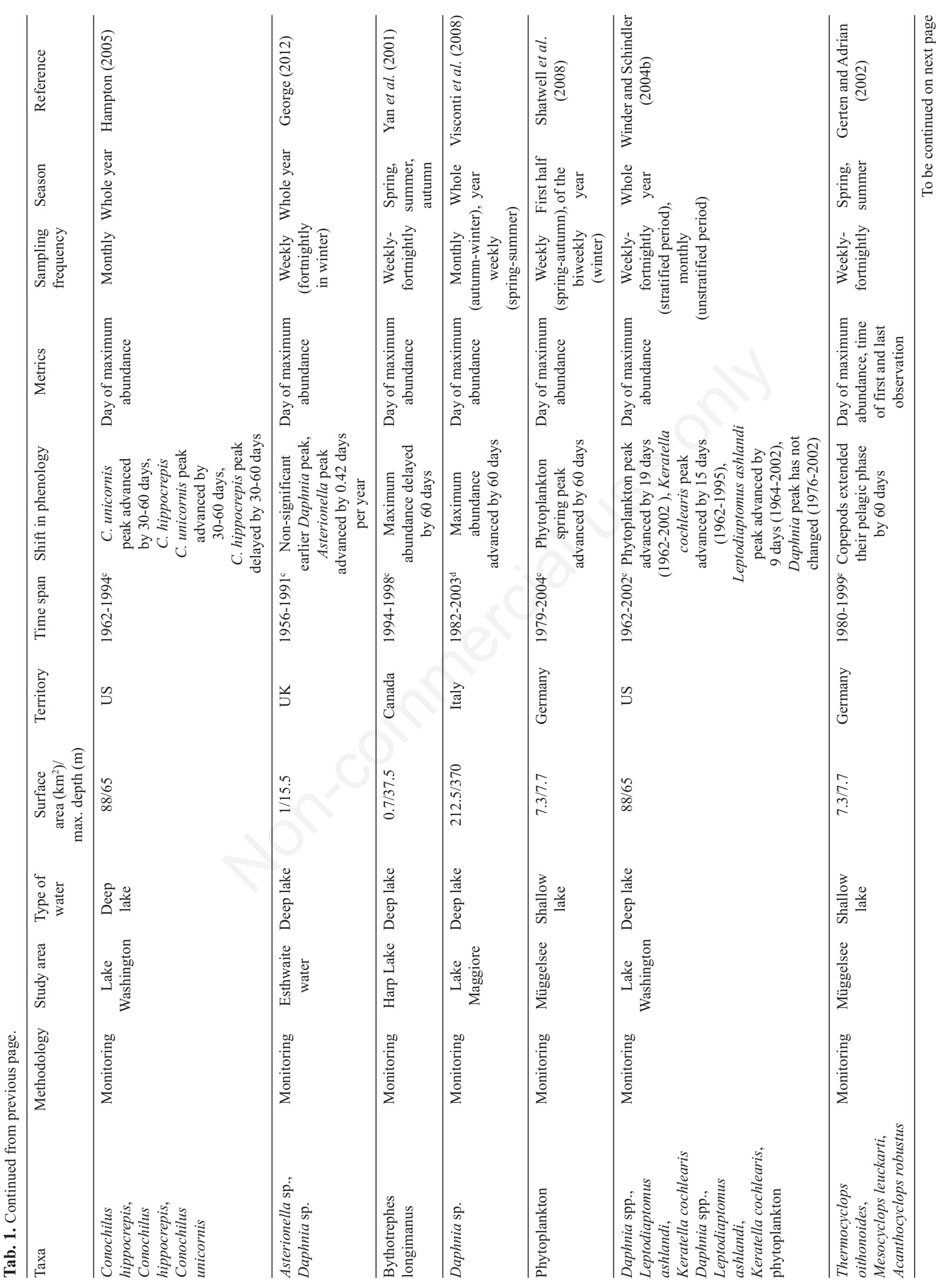




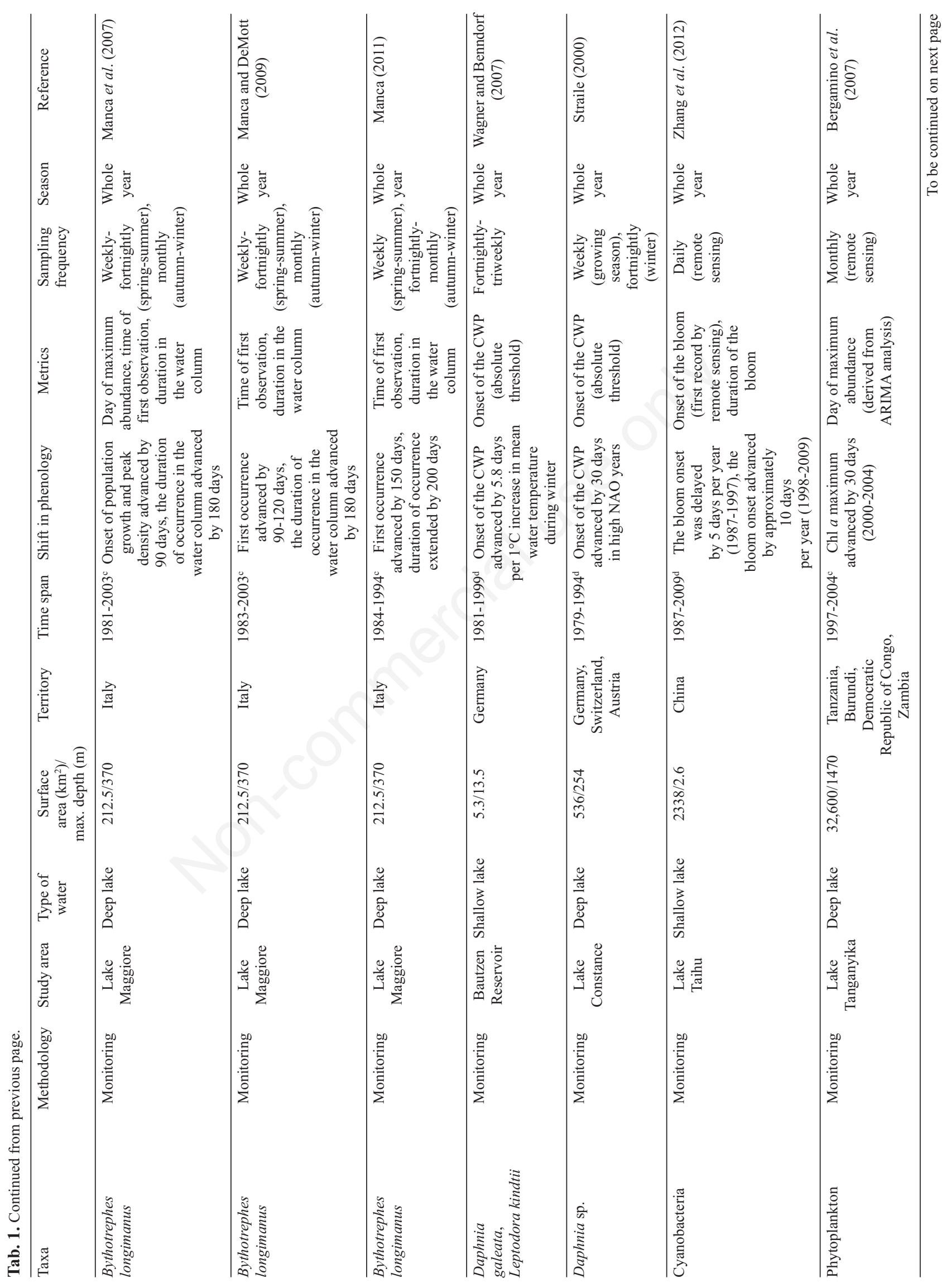




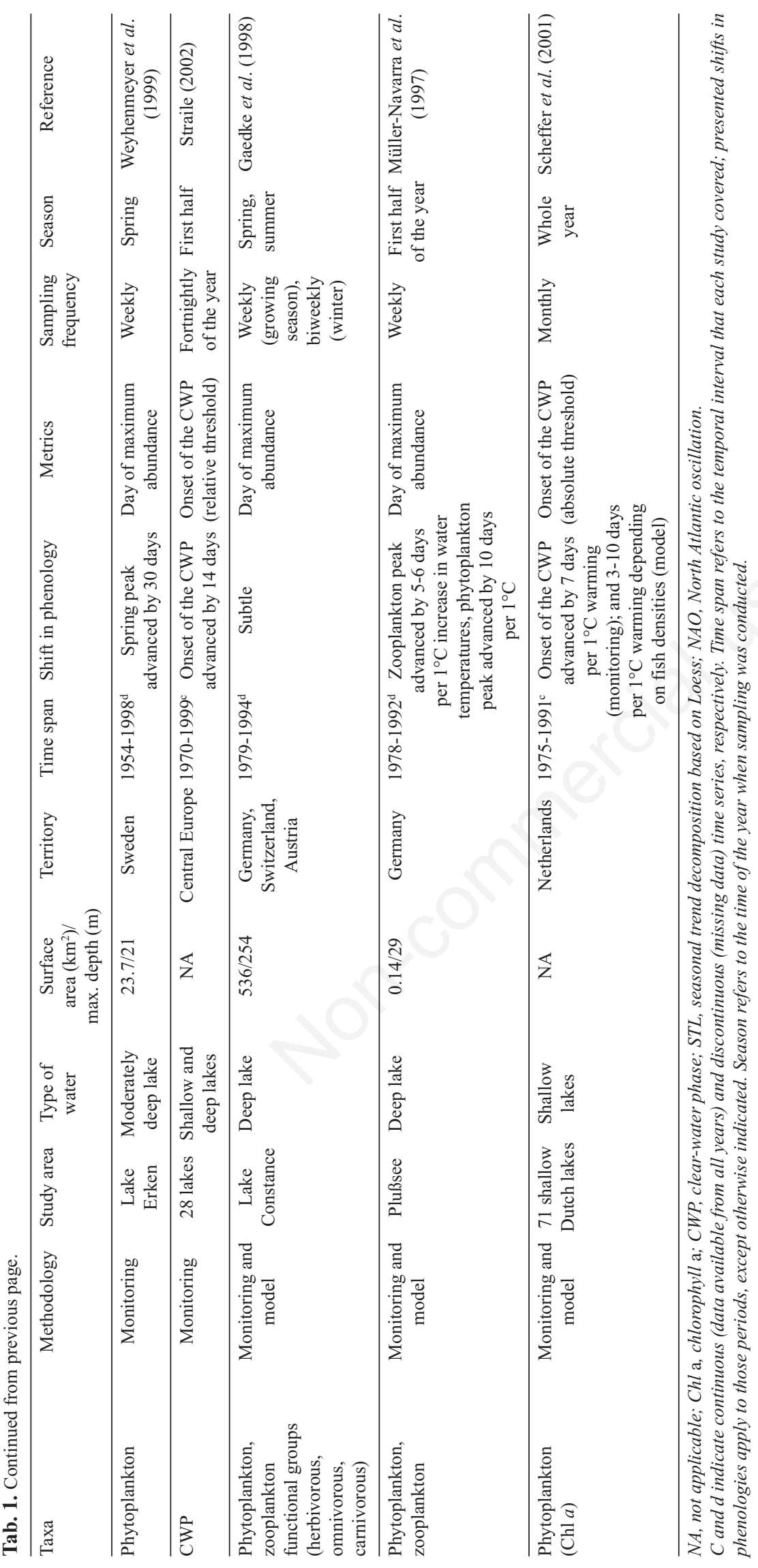


In the following we are going to identify the possible drivers of phenology in freshwater plankton. In deep lakes, algal growth in spring is initiated by the stratification of the water column allowing algal cells to be exposed to higher light levels (e.g. Gaedke et al., 1998). In a field experiment, Berger et al. (2007) showed that mixing and temperatures independently shape seasonal timing of plankton during spring. While deeper mixing delayed seasonal timing of phytoplankton and Daphnia, the temperature effect was detected in Daphnia only. The model of Peeters et al. (2007a) confirmed those findings in phytoplankton of Lake Constance. Tirok and Gaedke (2006) showed that weak mixing promoted earlier growth of phytoplankton, ciliates and rotifers despite low temperatures, but prevented Daphnia growth at the same time in Lake Constance. In non-stratifying shallow lakes, temperature has a more direct effect, primary production is not light-limited by stratification constraints, rather by self-shading, turbidity and depth, the major precursor of algal growth, however, can be the availability of nutrients (Scheffer et al., 1993). Earlier seasonal timing of zooplankton species can be either a direct effect of temperature rise (Gaedke et al., 1998) or an indirect effect via altered bottom up or top-down forcing (Manca et al., 2007; Visconti et al., 2008).

The phenology of plankton is subject to the phenology of resources and predators as well. Onset of population growth and peak densities of Bythotrephes longimanus advanced significantly with an increase of its duration of occurrence in Lake Maggiore, all resulted from an increase in the duration of the thermal refuge from predators (Manca et al., 2007; Manca and DeMott, 2009). Leptodora kindtii predation on Daphnia galeata advanced by 13 days per degree warming in Bautzen Reservoir, Germany (Wagner and Benndorf, 2007). It is thus clear that, the phenology of predator and prey responds differently to these changes in abiotic conditions. In order to measure this mismatch, Visser and Both (2005) proposed to assess the shift in phenology of species' food abundance, which they call a yardstick that will reflect a species success or failure to match its environment under climate change. Such decouplings between zooplankton and their algal prey were found in Lake Washington (Winder and Schindler, 2004a, 2004b), and in Esthwaite Water (George, 2012). Theoretical studies also suggest a potential for trophic mismatches in zooplankton-phytoplankton interactions in response to climate change (De Senerpont Domis et al., 2007; Mooij et al., 2007).

Cues for emergence of resting stages of zooplankton are likely to vary with warming climate, whose temperature and photoperiod are readily relevant to phenology. Spring warming is likely to induce earlier emergence from resting stages (Chen and Folt, 2002; Gerten and Adrian,

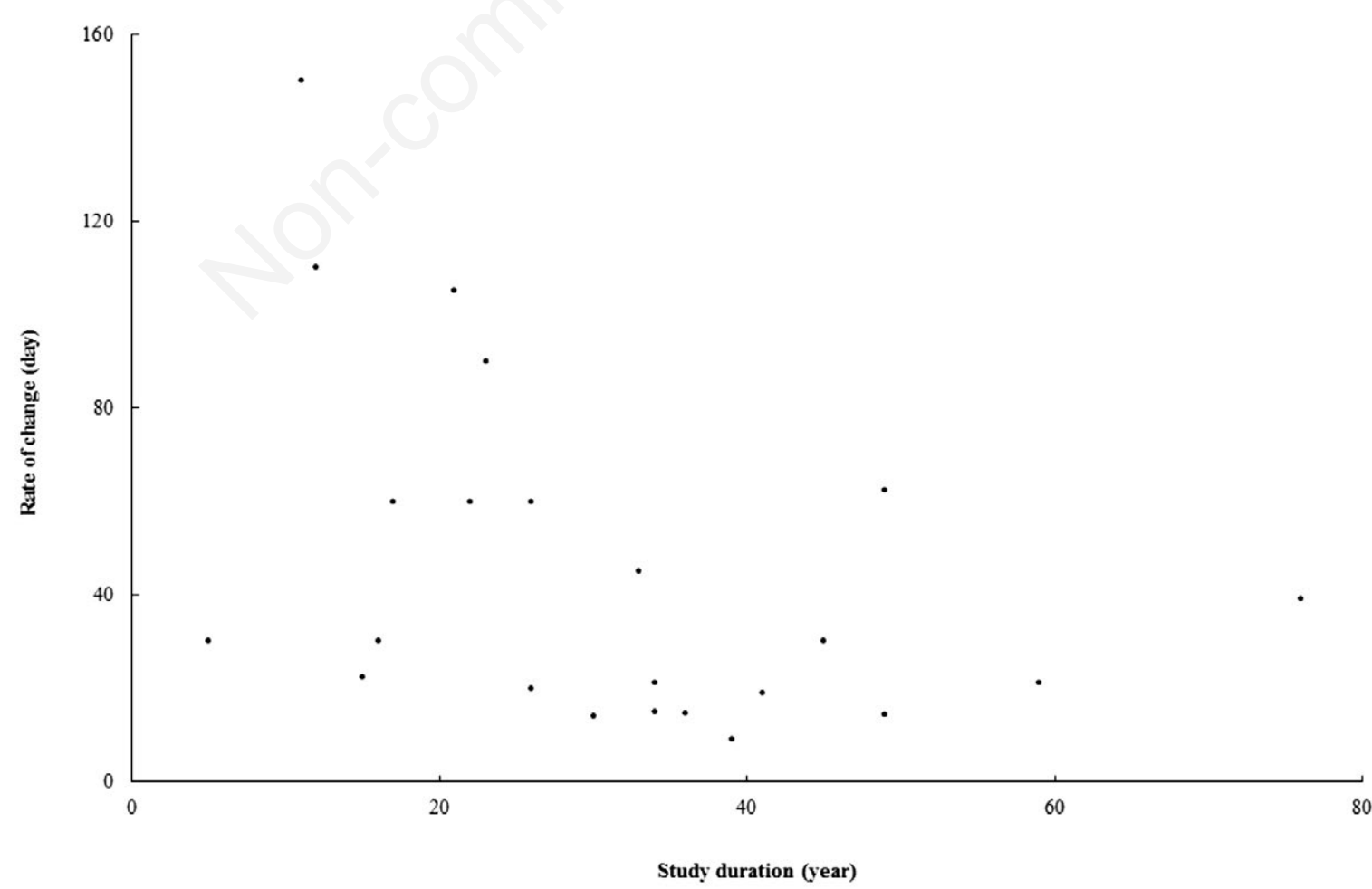

Fig. 3. Rates of advance in phenology of freshwater plankton vs study duration. 
2002). Increased temperatures and shorter photoperiod have found to decrease Daphnia emergence from resting eggs, while rotifers were less affected (Dupuis and Hann, 2009). Earlier ice-out was associated with increased hatchling abundance of Daphnia pulicaria in both the laboratory and in Oneida Lake (Cáceres and Schwalbach, 2001), suggesting a possibility to advance phenological events in this species.

Climate warming can have complex interactive effects with nutrient load (and other anthropogenic pressures), the latter potentially masking the effect of climate. Whether climate or nutrients have a stronger impact on plankton phenologies is a question that has not yet been answered: emerging evidence exists for either cases (Thackeray et al., 2008; Feuchtmayr et al., 2010; Desortová and Puncochár, 2011; Shimoda et al., 2011; Sipkay et al., 2012; Zhang et al., 2012).

\section{CONCLUSIONS}

\section{Spatial setting and contribution of different taxonomic groups}

A question remains to be answered: why is the geographical distribution of phenological studies skewed toward Central Europe? Simply because in Central Europe people have long been engaged in limnology and thus have long time series to analyse? Or is it because the impact of climate change varies locally and systems may differ in the magnitude of response and Central Europe has been a hot spot? The answer lies in climatology from which is clear that despite climate anomalies, other parts of the globe and the rest of Europe experienced climate change as well. Demonstration of global fingerprints of climate change on animals and plants (Walther et al., 2002; Parmesan and Yohe, 2003; Root et al., 2003) served evidence for the global impact. If this is true, and obviously it is, we assume that the number of studies documenting changes in phenology will increase worldwide supposing emerging (or at least continuing) science funding programmes.

Overwhelming evidence for climate change impacts on phenology comes from data gathered in lakes, with rivers being largely neglected objects in this respect. The few examples picked up in this paper, however, add to the body of evidence that running waters may experience changes in plankton phenology with rates comparable to those recorded in deep lakes. The longitudinal dimension represents an additional component in rivers, e.g. the longitudinal variation in community dynamics may influence plankton phenology.

While there is a need for continuing studies focusing on individual species, much of our recent understanding of plankton phenology derives from studies confined to daphnids; other species, particularly ciliates, have been given much less attention. Phytoplankton studies, by necessity, used multi-species approaches more frequently, but diatoms and blue-greens prevail. In part this is certainly because these groups are dominant in the systems under study. Measuring responses of functional groups can be quite useful not only in ecological models, where this is often the only way to do it, but those groups may reflect the response of the community more accurately than singular species do. Functional groups in freshwater phytoplankton have been defined (Reynolds et al., 2002) and updated (Padisák et al., 2009), such groups in zooplankton, however, have not yet been fully developed (Barnett et al., 2007). Applying those functional groups in climate change studies may challenge our understanding in this field.

\section{Temporal setting}

We demonstrated that increasing study duration was not coupled either with increasing contribution of discontinuous data or with increasing rates of phenological changes. The length of the study period does not seem to severely modify final conclusions assuming that the data are continuous and the time period covered is large enough. Rates of phenological changes, however, may vary over time (Thackeray et al., 2008), thus, caution is needed when rates are contrasted among different studies (Thackeray et al., 2010). A convincing example of temporal variation in environmental forcing is the phenomenon of large-scale climatic fluctuations. The winter NAO index experienced a positive phase over the 1970s, 1980s and 1990s bringing milder and wetter winters to western and northern Europe (Hurrell, 1995). As a result, the spring CWP advanced in both shallow and deep lakes (e.g. Straile, 2000, 2002; Wagner and Benndorf, 2007). Also note, that the 1970s and 1980s correspond with a bloom of long-term studies in the selected literature (Fig. 2). The mean and the median of time span the studies covered (27, and 23 years, respectively) meet assumptions of long-term studies. In freshwater macroinvertebrates, Jackson and Füreder (2006) defined a priori a study long-term when it spanned $\geq 5$ years. The long term ecological research (LTER) programme in the US considers time-scales spanning decades to centuries. Perhaps the most influential papers on phenological trends across a wide range of organisms and areas included data into the meta-analyses those spanned at least 10 years (Root et al., 2003), and 20 years (Parmesan and Yohe, 2003), respectively.

Much of the selected papers derived their findings from samples collected at weekly and fortnightly intervals at least during the growing season, which is a common and recognised method in limnology, although significant variation in community dynamics of zooplankton may remain hidden at fortnightly sampling (Vadadi-Fülöp et al., 2010).

Remote sensing has become a powerful tool to mea- 
sure chlorophyll $a$ content of inland waters (Kloiber et al., 2002; Nelson et al., 2003; Tyler et al., 2006) and provides temporally high-resolution data over large areas, even on a daily basis (Zhang et al., 2012). This makes it particularly valuable for climate change studies despite its drawbacks (spatial resolution, limited biological relevance, cloud cover, etc.). One of the most frequently used satellite data, Landsat has a temporal resolution of 16 days and a spatial resolution of $30 \mathrm{~m}$. The MODIS sensor provides daily measures, although with a relatively course spatial resolution of $1000 \mathrm{~m}$, but it can still be used for remote sensing of lakes with a minimum surface area of a few thousand hectars (Brezonik et al., 2005). There is a growing effort to integrate remote sensing techniques into the implementation of water quality assessment programmes (Koponen et al., 2002; Kloiber et al., 2002; Nelson et al., 2003). Despite the availability of satellite data, only two papers (Bergamino et al., 2007; Zhang et al., 2012) adopted this approach to quantify phytoplankton blooms. In the future, with improving methodologies and access to satellite data, remote sensing will have much more contribution to the field.

\section{Quantitative data of phenology shift and measures of phenological trends}

By considering both multi- and single-species studies, we demonstrated that freshwater plankton have experienced a mean advance of 1.5 days per year in seasonal timing over the study period presented in Tab. 1. This finding includes rates of advances and delays as well, but we did not standardised those data either with the possible number of nonresponding species or with the lenghts and periods of time series. Furthermore, it does not include findings of some half of the selected papers because of methodological constraints. However, the goal of this study, as defined in the introductory section, was not to perform a comprehensive meta-analysis, rather to delineate recent trends in plankton phenology studies (in the context of climate change), so as to find gaps and formulate possible future directions to fill them. Demonstrated rates of phenological changes in freshwater plankton exceeded those of marine plankton [Edwards and Richardson (2004), meta-analysis: peaks 10-27 days earlier; Richardson (2008), review: peaks 10-60 days earlier]. Global response of plant and animal species, determined by some enormous meta-analyses, ranged from 2.3 to 5.1 days per decade (Parmesan and Yohe, 2003; Root et al., 2003; Parmesan, 2007). The calculated rate of earlier seasonal timing in freshwater plankton (mean $=1.5$ days per year; median $=0.7$ days per year) is beyond the global average. Again, we should underline that our calculations are not based on a meta-analysis of raw data, nor are they standardised to balance the effects of nonresponding species, length and period of time series.
Another major factor determining estimated rates of phenological trends is the measure employed to quantify seasonal timing. Thackeray et al. (2012) distinguished among three major categories of metrics: i) the onset of the spring population development; ii) the timing of maximum abundance; and iii) the central point of the growing season. As we have already demonstrated, plankton studies have favoured the second method. A large number of papers did not use different metrics as a measure of phenological changes. The day of maximum abundance was the most simple and most favoured measure of phenological changes in the selected literature. Although useful, it does not capture the temporal dynamics of population growth, and is not sensitive to multiple abundance peaks. The central tendency method determines the central point of the growing season (Edwards and Richardson, 2004) and thus considers the entire growing season or an arbitrarily selected period. Thackeray et al. (2008) found statistically significant correlation betweeen the two methods (day of maximum abundance, central tendency) when the inter-annual variation in timing of phytoplankton blooms was considered. The onset of the CWP corresponds to minimum phytoplankton abundance and consequently assumes a maximum herbivore abundance (mainly Daphnia) and thus can be quite an appropriate measure for the timing of maximum abundance of zooplankton (assuming that zooplankton in this period is mainly composed of herbivores and the onset of CWP is caused by grazing). This is a rather fuzzy approximation of zooplankton phenology; still, it is relatively simply to measure as a Secchi disk reading. Examples come from the shallow Bautzen Reservoir (Wagner and Benndorf, 2007), deep Lake Constance (Straile, 2000), and a set of shallow Dutch lakes (Scheffer et al., 2001). Only few studies used relative thresholds (e.g. occurrence of 10 and $25 \%$ of maximum abundance) to determine the onset of population growth (Sipkay et al., 2012; Thackeray et al., 2012), despite their relevance when decadal time series are to be analysed. Similarly, few studies considered whether and how the duration of the population of some species in the water column has changed over recent decades (Gerten and Adrian, 2002; Manca et al., 2007; Manca and DeMott, 2009; Manca, 2011). Note, however, that one of the most striking examples of phenological changes derives from the metrics discussed above (Manca, 2011).

\section{Gaps to be filled and future directions}

Our current understanding of plankton phenology is limited to a rather narrow range of waters, of which running waters have been particularly neglected objects despite accumulating evidence for their vulnerability to climate change. To overcome this issue, new monitoring programmes should be launched, already existing programmes sho- 
uld be maintained and, perhaps most importantly, there is a need to deliver long-term data and put them into a global change perspective. We guess that far more time series have been gathered than published and, therefore, we encourage ecologists to have a look at their data.

Although multi- and single-species studies continue to remain useful, the application of plankton functional groups in climate change studies will allow for a more thorough understanding of how climate change appears to shape the phenology of different taxa and trophic levels.

Remote sensing techniques with improving temporal and spatial resolution will allow for a more precise estimation of phytoplankton bloom phenology. Continuing longterm monitoring programmes, in turn, can support the development of new models to retrieve chlorophyll concentration from satellite images. Owing to the multidisciplinary nature of such an approach, we encourage ecologists to contact specialists of the field. Considering the charges of accessing satellite data of adequate resolution, this assumes continuous support from funding agencies.

Much of our recent understanding of seasonal timing under climate change derives from the spring period, and much less attention has been given to the autumn and winter periods, despite their significance for zooplankton overwintering success (Chen and Folt, 1996). Ecologists should extend their study period to the entire year as far as possible (excellent examples are given in Tab. 1).

A healthy combination of empirical, experimental and theoretical approaches will definitely bridge the gap among scientists and challenge our way of thinking in plankton phenology. The signs of this work are already apparent in the literature.

We warmly recommend to move beyond using the most common and simple metrics (the day of maximum abundance) toward the application of various metrics, including relative thresholds, e.g. defining the Julian day when $25 \%$ of total annual abundance is reached. The onset of the CWP, with its relative simplicity, will definitely gain more power in the future. The coupling between the CWP and the NAO (highlighted earlier) strengthens our belief in the applicability of such metrics. In some (eutrophic) systems, CWP cannot be defined and hence it has a limited applicability as a metric.

Decoupling of trophic interactions has become one of the most challenging issues over recent years, and has been documented over different taxa and trophic levels (Visser et al., 2006; Memmott et al., 2007; Liu et al., 2011). Evidence will definitely further accumulate for freshwater plankton as well. Time will tell, however, how frequent it can be. What emerges from this review is that much more effort should be given to the study of this mismatch by comparing rates of phenological changes across different trophic groups. Apart from mismatches also new matches will occur (Winder and Schindler, 2004b).
Hatching cues and associated emergence dynamics in zooplankton have been given minor attention yet. Excellent examples are in Chen and Folt (2002), De Senerpont Domis et al. (2007), Dupuis and Hann (2009). Hence, integrating the study of benthic-pelagic coupling into phenological research efforts will improve our understanding in the field.

While there has been a growing effort to assemble the puzzle in terrestrial and marine systems, we still lack a state-of-the-art meta-analysis in freshwater plankton [but see Straile (2002) as an excellent initiative]. We hope that this paper will facilitate further advance in this rapidly expanding field of ecology.

Finally, the major pitfall remains the publication bias toward documentation of phenological changes in response to climate change, although there is a growing effort to overcome this difficulty (Parmesan and Yohe, 2003; Thackeray et al., 2010). Furthermore, documented changes in phenology should not be attributed to climate warming without any mechanistic explanation.

\section{ACKNOWLEDGMENTS}

This work was supported by the Bolyai János Research Scholarship of the Hungarian Academy of Sciences. We are indebted to Tim Hague for helpful comments on the language of the manuscript. We thank two anonymous reviewers for improving the manuscript.

\section{REFERENCES}

Barnett AJ, Finlay K, Beisner BE, 2007. Functional diversity of crustacean zooplankton communities: towards a trait-based classification. Freshwater Biol. 52:796-813.

Bergamino N, Loiselle SA, Cózar A, Dattilo AM, Bracchini L, Rossi C, 2007. Examining the dynamics of phytoplankton biomass in Lake Tanganyika using empirical orthogonal functions. Ecol. Model. 204:156-162.

Berger SA, Diehl S, Stibor H, Trommer G, Ruhenstroth M, 2010. Water temperature and stratification depth independently shift cardinal events during plankton spring succession. Global Change Biol. 16:1954-1965.

Berger SA, Diehl S, Stibor H, Trommer G, Ruhenstroth M, Wild A, Weigert A, Jäger CG, Striebel M, 2007. Water temperature and mixing depth affect timing and magnitude of events during spring succession of the plankton. Oecologia 150: 643-654.

Brezonik P, Menken KD, Bauer M, 2005. Landsat-based remote sensing of lake water quality characteristics, including chlorophyll and colored dissolved organic matter (CDOM). Lake Reservoir Manag. 21:373-382.

Cáceres CE, Schwalbach MS, 2001. How well do laboratory experiments explain field patterns of zooplankton emergence? Freshwater Biol. 46:1179-1189.

Chen CY, Folt CL, 1996. Consequences of fall warming for zooplankton overwintering success. Limnol. Oceanogr. 41: 1077-1086.

Chen CY, Folt CL, 2002. Ecophysiological responses to warm- 
ing events by two sympatric zooplankton species. J. Plankton Res. 24:579-589.

Cushing DH, 1969. The regularity of the spawning season of some fishes. ICES J. Mar. Sci. 33:81-92.

De Senerpont Domis LNW, Mooij M, Hülsmann S, Van Nes EH, Scheffer M, 2007. Can overwintering versus diapausing strategy in Daphnia determine match-mismatch events in zooplankton-algae interactions? Oecologia 150:682-698.

Desortová B, Puncochár P, 2011. Variability of phytoplankton biomass in a lowland river: response to climate conditions. Limnologica 41:160-166.

Dupuis AP, Hann BJ, 2009. Climate change, diapause termination and zooplankton population dynamics: an experimental and modelling approach. Freshwater Biol. 54:221-235.

Durant JM, Hjermann DO, Ottersen G, Stenseth NC, 2007. Climate and the match or mismatch between predator requirements and resource availability. Clim. Res. 33:271-283.

Edwards M, Richardson A, 2004. Impact of climate change on marine pelagic phenology and trophic mismatch. Nature 430:881-884.

Elliott JA, 2012. Predicting the impact of changing nutrient load and temperature on the phytoplankton of England's largest lake, Windermere. Freshwater Biol. 57:400-413.

Elliott JA, Jones ID, Thackeray SJ, 2006. Testing the sensitivity of phytoplankton communities to changes in water temperature and nutrient load, in a temperate lake. Hydrobiologia 559:401-411.

Elliott JA, Thackeray SJ, Huntingford C, Jones RG, 2005. Combining a regional climate model with a phytoplankton community model to predict future changes in phytoplankton in lakes. Freshwater Biol. 50:1404-1411.

Feuchtmayr H, Moss B, Harvey I, Moran R, Hatton K, Connor L, Atkinson D, 2010. Differential effects of warming and nutrient loading on the timing and size of the spring zooplankton peak: an experimental approach with hypertrophic freshwater mesocosms. J. Plankton Res. 32:1715-1725.

Feuchtmayr H, Thackeray SJ, Jones ID, De Ville M, Fletcher J, James B, Kelly J, 2012. Spring phytoplankton phenology: are patterns and drivers of change consistent among lakes in the same climatological region? Freshwater Biol. 57:331-344.

Gaedke U, Ollinger D, Bauerle E, Straile D, 1998. The impact of the interannual variability in hydrodynamic conditions on the plankton development in Lake Constance in spring and summer. Adv. Limnol. 53:565-585.

George DG, 2012. The effect of nutrient enrichment and changes in the weather on the abundance of Daphnia in Esthwaite Water, Cumbria. Freshwater Biol. 57:360-372.

Gerten D, Adrian R, 2002. Species-specific changes in the phenology and peak abundance of freshwater copepods in response to warm summers. Freshwater Biol. 47:2163-2173.

Hampton SE, 2005. Increased niche differentiation between two Conochilus species over 33 years of climate change and food web alteration. Limnol. Oceanogr. 50:421-426.

Hays GC, Richardson AJ, Robinson C, 2005. Climate change and marine plankton. Trends Ecol. Evol. 20:337-344.

Huber V, Adrian R, Gerten D, 2008. Phytoplankton response to climate warming modified by trophic state. Limnol. Oceanogr. 53:1-13.

Hurrell JW, 1995. Decadal trends in the North Atlantic oscillation: regional temperatures and precipitation. Science 269:676-679.

Jackson JK, Füreder L, 2006. Long-term studies of freshwater macroinvertebrates: a review of the frequency, duration and ecological significance. Freshwater Biol. 51:591-603.
Kloiber SM, Brezonik PL, Olmanson LG, Bauer ME, 2002. A procedure for regional lake water clarity assessment using Landsat multispectral data. Remote Sens. Environ. 82:38-47.

Koponen S, Pulliainen J, Kallio K, Hallikainen M, 2002. Lake water quality classification with airborne hyperspectral spectrometer and simulated MERIS data. Remote Sens. Environ. 79:51-59.

Liu Y, Reich PB, Li G, Sun S, 2011. Shifting phenology and abundance under experimental warming alters trophic relationships and plant reproductive capacity. Ecology 92:1201-1207.

Manca M, 2011. Invasion and re-emergences: an analysis of the success of Bythotrephes in Lago Maggiore (Italy). J. Limnol. 70:76-82.

Manca M, DeMott WR, 2009. Response of the invertebrate predator Bythotrephes to a climate-linked increase in the duration of a refuge from fish predation. Limnol. Oceanogr. 54:2506-2512.

Manca M, Portogallo M, Brown ME, 2007. Shifts in phenology of Bythotrephes longimanus and its modern success in Lake Maggiore as a result of changes in climate and trophy. J. Plankton Res. 29:515-525.

Meis S, Thackeray SJ, Jones ID, 2009. Effects of recent climate change on phytoplankton phenology in a temperate lake. Freshwater Biol. 54:1888-1898.

Memmott J, Craze PG, Waser NM, Price MV, 2007. Global warming and the disruption of plant-pollinator interactions. Ecol. Lett. 10:710-717.

Mooij WM, Janse JH, De Senerpont Domis LN, Hülsmann S, Ibelings BW, 2007. Predicting the effect of climate change on temperate shallow lakes with the ecosystem model PCLake. Hydrobiologia 584:443-454.

Müller-Navarra DC, Güss S, Von Storch H, 1997. Interannual variability of seasonal succession events in a temperate lake and its relation to temperature variability. Global Change Biol. 3:429-438.

Nelson SAC, Soranno PA, Cheruvelil KS, Batzli SA, Skole DL, 2003. Regional assessment of lake water quality using satellite remote sensing. J. Limnol. 62(Suppl.1):27-32.

Padisák J, Crossetti LO, Naselli-Flores L, 2009. Use and misuse in the application of the phytoplankton functional classification: a critical review with updates. Hydrobiologia 621:1-19.

Parmesan C, 2007. Influences of species, latitudes and methodologies on estimates of phenological response to global warming. Global Change Biol. 13:1860-1872.

Parmesan C, Yohe G, 2003. A globally coherent fingerprint of climate change impacts across natural systems. Nature 421:37-42.

Peeters F, Straile D, Lorke A, Livingstone DM, 2007a. Earlier onset of the spring phytoplankton bloom in lakes of the temperate zone in a warmer climate. Global Change Biol. 13:1898-1909.

Peeters F, Straile D, Lorke A, Ollinger D, 2007b. Turbulent mixing and phytoplankton spring bloom development in a deep lake. Limnol. Oceanogr. 52:286-298.

Reynolds CS, Huszar V, Kruk C, Naselli-Flores L, Melo S, 2002. Towards a functional classification of the freshwater phytoplankton. J. Plankton Res. 24:417-428.

Richardson AJ, 2008. In hot water: zooplankton and climate change. ICES J. Mar. Sci. 65:279-295.

Root TL, Price JT, Hall KR, Schneider SH, Rosenzweig C, Pounds A, 2003. Fingerprints of global warming on wild animals and plants. Nature 421:57-60.

Schalau K, Rinke K, Straile D, Peeters F, 2008. Temperature is the key factor explaining interannual variability of Daphnia 
development in spring: a modelling study. Oecologia 157:531-543.

Scheffer M, Hosper SH, Meijer ML, Moss B, Jeppesen E, 1993. Alternative equilibria in shallow lakes. Trends Ecol. Evol. $8: 275-279$.

Scheffer M, Straile D, Van Nes EH, Hosper H, 2001. Climatic warming causes regime shifts in lake food webs. Limnol. Oceanogr. 46:1780-1783.

Seebens H, Straile D, Hoegg R, Stich HB, Einsle U, 2007. Population dynamics of a freshwater calanoid copepod: complex responses to changes in trophic status and climate variability. Limnol. Oceanogr. 52:2364-2372.

Shatwell T, Köhler J, Nicklisch A, 2008. Warming promotes cold-adapted phytoplankton in temperate lakes and opens a loophole for Oscillatoriales in spring. Global Change Biol. 14:2194-2200.

Shimoda Y, Azim ME, Perhar G, Ramin M, Kenney MA, Sadraddini S, Gudimov A, Arhonditsis GB, 2011. Our current understanding of lake ecosystem response to climate change: what have we really learned from the north temperate deep lakes? J. Great Lakes Res. 37:173-193.

Sipkay C, Horváth L, Nosek J, Oertel N, Vadadi-Fülöp CS, Farkas E, Drégelyi-Kiss Á, Hufnagel L, 2008. Analysis of climate change scenarios based on modelling of the seasonal dynamics of a Danubian copepod species. Appl. Ecol. Env. Res. 6:101-108.

Sipkay C, Kiss KT, Vadadi-Fülöp C, Homoródi R, Hufnagel L, 2012. Simulation modeling of phytoplankton dynamics in a large eutrophic river, Hungary - Danubian Phytoplankton Growth Model DPGM. Biologia 67:323-337.

Sommer U, Gliwicz ZM, Lampert W, Duncan A, 1986. The PEG-model of seasonal succession of planktonic events in fresh waters. Arch. Hydrobiol. 106:433-471.

Straile D, 2000. Meteorological forcing of plankton dynamics in a large and deep continental European lake. Oecologia 122:44-50.

Straile D, 2002. North Atlantic oscillation synchronizes foodweb interactions in central European lakes. P. Roy. Soc. Lond. B. Bio. 269:391-395.

Straile D, Geller W, 1998. The response of Daphnia to changes in trophic status and weather patterns: a case study from Lake Constance. ICES J. Mar. Sci. 55:775-782.

Thackeray SJ, Henrys PA, Jones ID, Feuchtmayr H, 2012. Eight decades of phenological change for a freshwater cladoceran: what are the consequences of our definition of seasonal timing? Freshwater Biol. 57:345-359.

Thackeray SJ, Jones ID, Maberly SC, 2008. Long-term change in the phenology of spring phytoplankton: species-specific responses to nutrient enrichment and climatic change. J. Ecol. 96:523-535.

Thackeray SJ, Sparks TH, Frederiksen M, Burthe S, Bacon PJ, Bell JR, Botham MS, Brereton TM, Bright PW, Carvalho L, Clutton-Brock T, Dawson A, Edwards M, Elliott JM, Harrington R, Johns D, Jones ID, Jones JT, Leech DI, Roy DB, Scott WA, Smith M, Smithers RJ, Winfield IJ, Wanless S, 2010. Trophic level asynchrony in rates of phenological change for marine, freshwater and terrestrial environments. Global Change Biol. 16:3304-3313.
Tirok K, Gaedke U, 2006. Spring weather determines the relative importance of ciliates, rotifers and crustaceans for the initiation of the clear-water phase in a large, deep lake. J. Plankton Res. 28:361-373.

Tyler AN, Svab E, Preston T, Présing M, Kovács WA, 2006. Remote sensing of the water quality of shallow lakes: a mixture modelling approach to quantifying phytoplankton in water characterized by high-suspended sediment. Int. J. Remote Sens. 27:1521-1537.

Vadadi-Fülöp C, Hufnagel L, Zsuga K, 2010. Effect of sampling effort and sampling frequency on the composition of the planktonic crustacean assemblage: a case study of the River Danube. Environ. Monit. Assess. 163:125-138.

Vadadi-Fülöp C, Sipkay C, Mészáros G, Hufnagel L, 2012. Climate change and freshwater zooplankton: what does it boild down to? Aquat. Ecol. 46:501-519.

Vadadi-Fülöp C, Türei D, Sipkay C, Verasztó C, Drégelyi-Kiss Á, Hufnagel L, 2009. Comparative assessment of climate change scenarios based on aquatic food web modeling. Environ. Model. Assess. 14:563-576.

Visconti A, Manca M, De Bernardi R, 2008. Eutrophicationlike response to climate warming: an analysis of Lago Maggiore (N. Italy) zooplankton in contrasting years. J. Limnol. 67:87-92.

Visser ME, Both C, 2005. Shifts in phenology due to global climate change: the need for a yardstick. P. Roy. Soc. Lond. B. Bio. 272:2561-2569.

Visser ME, Holleman LJM, Gienapp P, 2006. Shifts in caterpillar biomass phenology due to climate change and its impact on the breeding biology of an insectivorous bird. Oecologia 147:164-172.

Wagner A, Benndorf J, 2007. Climate-driven warming during spring destabilises a Daphnia population: a mechanistic food web approach. Oecologia 151:351-364.

Walther GR, Post E, Convey P, Menzel A, Parmesan C, Beebee TJC, Fromentin J-M, Hoegh-Guldberg O, Bairlein F, 2002. Ecological responses to recent climate change. Nature 416:389-395.

Weyhenmeyer GA, Blenckner T, Pettersson K, 1999. Changes of the plankton spring outburst related to the North Atlantic oscillation. Limnol. Oceanogr. 44:1788-1792.

Winder M, Schindler DE, 2004a. Climate change uncouples trophic interactions in an aquatic ecosystem. Ecology 85:2100-2106.

Winder M, Schindler DE, 2004b. Climatic effects on the phenology of lake processes. Global Change Biol. 10:1844-1856.

Wojtal-Frankiewicz A, 2012. The effects of global warming on Daphnia spp. population dynamics: a review. Aquat. Ecol. 46:37-53.

Yan ND, Blukacz A, Sprules WG, Kindy PK, Hackett D, Girard RE, Clark BJ, 2001. Changes in zooplankton and the phenology of the spiny water flea, Bythotrephes, following its invasion of Harp Lake, Ontario, Canada. Can. J. Fish. Aquat. Sci. 58:2341-2350.

Zhang M, Duan H, Shi X, Yu Y, Kong F, 2012. Contributions of meteorology to the phenology of cyanobacterial blooms: implications for future climate change. Water Res. 46:442-452. 